\title{
Editorial
}

\section{We're on the Web!}

At present, there is increasing pressure on researchers and authors in the field of medical science to have fast access to data generated by other workers. One way in which this has become possible recently is via The Internet or Information Super Highway. The basis of this facility is that a national and international network of computers is interlinked, enabling vast communication possibilities and the dissemination of enormous amounts of knowledge. The devices interlinked range from simple, domestic microcomputers to "supercomputers" as used in research and industry. Connection is made by modem and users gain entry to the Net by means of service providers, usually at a low financial cost. This gives access to an extraordinarily large amount of textual and graphic information, on a scale never previously possible in the history of Mankind. Another feature of the system is that subscribers can make use of e-mail, which is, in effect, a very inexpensive "mail-box", where incoming mail can be stored and browsed at leisure.

It is, therefore, timely that the current issue of $C M P$ has a leading article by Dr Jem Rashbass regarding The Internet in molecular medicine. He describes the great possible utilities in our field to researchers and those who are in training of Internet based information. By perhaps more than coincidence, then, we are delighted to announce that $\mathscr{F C P}$ and $C M P$ have become part of the Net. Readers and potential authors can now gain instant access to lists of recent and forthcoming papers, together with Instructions to Authors, by dialling our page. It will be most interesting to speculate regarding the future of this venture over the next five years.

The $\mathcal{F C P} / C M P$ page address is: http:// www.bmj.com/bmj/. 